\title{
Nine-Gene Molecular Signature Is Not Associated with Prostate Cancer Death in a Watchful Waiting Cohort
}

\section{Citation}

Mucci, L. A., Y. Pawitan, F. Demichelis, K. Fall, J. R. Stark, H.-O. Adami, S.-O. Andersson, et al. 2008. "Nine-Gene Molecular Signature Is Not Associated with Prostate Cancer Death in a Watchful Waiting Cohort." Cancer Epidemiology Biomarkers \& Prevention 17 (1): 249-51. https:// doi.org/10.1158/1055-9965.epi-07-0722.

\section{Permanent link}

http://nrs.harvard.edu/urn-3:HUL.InstRepos:41292882

\section{Terms of Use}

This article was downloaded from Harvard University's DASH repository, WARNING: This file should NOT have been available for downloading from Harvard University's DASH repository.

\section{Share Your Story}

The Harvard community has made this article openly available. Please share how this access benefits you. Submit a story. 


\title{
Nine-Gene Molecular Signature Is Not Associated with Prostate Cancer Death in a Watchful Waiting Cohort
}

\author{
Lorelei A. Mucci, 1,2,3 Yudi Pawitan, ${ }^{6}$ Francesca Demichelis, ${ }^{3,4,7}$ Katja Fall, ${ }^{6}$ \\ Jennifer R. Stark, ${ }^{1,2}$ Hans-Olov Adami, ${ }^{2,6}$ Swen-Olof Andersson, ${ }^{8}$ Ove Andrén, ${ }^{8}$ \\ Anna S. Eisenstein, ${ }^{1}$ Lars Holmberg, ${ }^{9}$ Wei Huang, ${ }^{3,4}$ Philip W. Kantoff,, 3 \\ Sven Perner, ${ }^{3,4,10,11}$ Meir J. Stampfer, ${ }^{1,2,3}$ Jan-Erik Johansson, ${ }^{8}$ \\ and Mark A. Rubin ${ }^{3,4,5,11}$
}

${ }^{1}$ Channing Laboratory, Department of Medicine, Brigham and Women's Hospital and Harvard Medical School; ${ }^{2}$ Department of Epidemiology, Harvard School of Public Health; ${ }^{3}$ Department of Pathology, Harvard Medical School; ${ }^{4}$ Department of Pathology, Brigham and Women's Hospital; ${ }^{5}$ Dana-Farber Cancer Institute, Boston, Massachusetts; ${ }^{6}$ Department of Medical Epidemiology and Biostatistics, Karolinska Institutet, Stockholm, Sweden; ${ }^{7}$ Bioinformatics Group, SRA, ITC-irst, Trento, Italy; ${ }^{8}$ Department of Urology, Örebro University Hospital, Örebro, Sweden; ${ }^{9}$ Regional Oncologic Centre, Uppsala University, Uppsala, Sweden; ${ }^{10}$ Department of Pathology, University of Ulm, Ulm, Germany; and ${ }^{11}$ Department of Pathology, Weill Medical Center of Cornell University, New York, New York

\begin{abstract}
Tumor molecular markers hold promise to distinguish potentially lethal from indolent prostate cancer and to guide treatment choices. A previous study identified a nine-gene molecular signature in tumors associated with prostate-specific antigen relapse after prostatectomy. We examined this molecular model in relation to prostate cancer death among 172 men
\end{abstract}

with initially localized disease. We quantified protein expression of the nine genes in tumors to classify progression risk. Accounting for clinical prognostic factors, the nine-gene model did not provide discrimination to predict lethal and indolent prostate cancer. (Cancer Epidemiol Biomarkers Prev 2008;17(1):249-51)

\section{Introduction}

Prostate cancer is the most common male cancer in westernized countries. Most men diagnosed in early stages experience slow-growing or indolent tumors even in the absence of therapy $(1,2)$. The rising incidence of prostate cancer, chiefly due to increased prostate-specific antigen (PSA) screening and diagnostic intensity, underscores the need to distinguish indolent from lethal prostate cancer to guide treatment decisions.

Clinical nomograms characterize progression risk using pretreatment clinical markers and have predictive power $(3,4)$, but molecular tumor markers hold promise to improve prognostication (5). A signature of advanced prostate cancer was recently identified by assessing gene expression at the transcriptome and proteome level. The nine-gene model identified markers that were altered in metastatic versus localized prostate cancer and predicted

Received 8/6/07; revised 10/23/07; accepted 10/31/07

Grant support: NIH/National Cancer Institute Prostate Specialized Programs of Research Excellence at the Dana-Farber/Harvard Cancer Center grant NCI P50 CA090381, NIH T32 Training Grant CA009001 (L.A.M.), NIH R01AG21404 (M.A.R. and F.D.), and Deutsche Forschungsgemeinschaft DFG PE1179/1-1 (S.P.). The costs of publication of this article were defrayed in part by the payment of page charges. This article must therefore be hereby marked advertisement in accordance with 18 U.S.C. Section 1734 solely to indicate this fact.

Requests for reprints: Lorelei A. Mucci, Channing Laboratory, Department of Medicine, Brigham and Women's Hospital and Harvard Medical School, 3rd Floor, 181 Longwood Avenue, Boston, MA 02115. Phone: 617-525-2132; Fax: 617-525-2008. E-mail: lmucci@hsph.harvard.edu

Copyright $(2008$ American Association for Cancer Research.

doi:10.1158/1055-9965.EPI-07-0722
PSA relapse after surgery in expression array datasets (6). Most men with PSA relapse, however, do not develop metastatic or lethal disease (7). Thus, we tested this molecular signature to predict prostate cancer death among men diagnosed with localized disease and followed prospectively for outcomes over 20 years.

\section{Materials and Methods}

Subjects. The Örebro Watchful Waiting Cohort $(2,8)$ comprises 172 Swedish men with localized (T1a/T1b) prostate cancer diagnosed incidentally by transurethral resection of the prostate for benign prostatic hyperplasia between 1977 and 1991. Following cancer diagnosis, the men were initially managed by watchful waiting and followed with careful monitoring by clinical exams, laboratory tests, and bone scans. Follow-up for development of distant metastases and death is complete through March 2006.

Immunohistochemistry. Archival formalin-fixed, paraffin-embedded tissue specimens were used to construct high-density tissue microarrays (TMA; ref. 8). Two $0.6-\mathrm{mm}$ tumor tissue cores from the dominant prostate cancer nodule of each case were included on TMAs (9). Using immunohistochemistry, we assayed tumor protein expression of the nine genes on TMA sections and assessed staining intensity (0-255) and percent of positive stained area $(0-100 \%)$ from scanned digital images of 
Table 1. Clinical characteristics comparing risk categories based on the nine-gene model, Örebro Watchful Waiting Cohort, 1977 to 2005

\begin{tabular}{lccc}
\hline & \multicolumn{3}{c}{$\begin{array}{c}\text { Risk classification based on } \\
\text { nine-gene model* }\end{array}$} \\
\cline { 2 - 4 } & $\begin{array}{c}\text { Lowest } \\
\text { risk (Q1) }\end{array}$ & $\begin{array}{c}\text { Intermediate } \\
\text { risk (Q3) }\end{array}$ & $\begin{array}{c}\text { Highest } \\
\text { risk (Q5) }\end{array}$ \\
\hline$n$ & 17 & 42 & 39 \\
Age at diagnosis (y) & $75.5(6.7)$ & $73.6(7.4)$ & $73.7(7.9)$ \\
Mean (SD) follow-up (y) & $8.4(6.2)$ & $8.2(6.1)$ & $6.9(5.2)$ \\
Gleason score (\%) & & & \\
$4-5$ & 5.9 & 16.7 & 0.0 \\
6 & 58.8 & 47.6 & 48.7 \\
7 & 29.4 & 19.1 & 25.6 \\
8 & 5.9 & 16.7 & 25.6 \\
Tumor extent (\%) & & & \\
$\quad 55 \%$ & 29.4 & 45.2 & 41.0 \\
$5-24.9 \%$ & 64.7 & 38.1 & 28.2 \\
$25-49.9 \%$ & 5.9 & 2.4 & 7.7 \\
$>50 \%$ & 0.0 & 14.3 & 23.1 \\
Nuclear grade (\%) & & & \\
I & 76.5 & 76.2 & 56.4 \\
II & 17.7 & 14.3 & 30.8 \\
III & 5.9 & 9.5 & 12.8 \\
\hline
\end{tabular}

* Risk classification is based on the molecular risk score divided into quintiles. For presentation, data from Q2 and Q4 are excluded.

TMA cores using the Chromavision image analysis system (10).

Statistical Analysis. Based on the cohort distribution, expression of each marker was divided into quartiles. Expression in the highest quartile for markers upregulated in metastatic versus localized prostate cancer (AMACR, Itga-5, cIAP, and krip1) received a score of 1 (0 otherwise), whereas expression in the lowest quartile for down-regulated markers (occludin, bm28, p62, lap2, and drbp76) received a score of 1 . We summed across each of the genes to create a summary molecular risk score and classified men as having a high, intermediate, or low risk of progression.

We used time-to-event analyses to evaluate the ability of the molecular signature to predict development of lethal prostate cancer. Hazard ratios [HR; 95\% confidence intervals $(95 \% \mathrm{CI})$ ] were used as effect measures from proportional hazards model. We compared ageadjusted (continuously) models with models also adjusted for clinical predictors: Gleason grade (categorically,
$4-5,6,7$, and $>8$ ), nuclear grade (categorically, grades I, II, and III), and tumor extent (categorically, $<5 \%, 5-24.9 \%$, $25-49.9 \%$, and $>50 \%$ ).

The study was approved by the institutional review boards at the collaborating U.S. and Swedish institutions.

\section{Results}

The mean (SD) age of the men at prostate cancer diagnosis was 74.1 (7.1) years. Of the 172 men with localized prostate cancer, 40 developed lethal disease. Mean time to development of metastatic disease was 7.6 years, and mean time from metastasis to time of death was 2.0 years. Men classified as higher risk of lethal prostate cancer based on the nine-gene signature tended to have tumors with higher Gleason grade, higher nuclear grade, and greater tumor extent than men classified at lower risk (Table 1).

First, we individually evaluated each of the gene markers to predict lethal prostate cancer. Dysregulation of cIAP (HR, 1.9; 95\% CI, 0.9-3.6) and Itga-5 (HR, 1.7; $95 \%$ CI, 0.8-3.3) were the strongest predictors of lethal prostate cancer, although neither was statistically significant.

The nine-gene model was modestly predictive of lethal disease. Of the 17 men classified as lowest risk by the nine-gene model, $11.8 \%$ died of cancer, whereas a larger percentage of men $(28.2 \%)$ classified as highest risk by the nine-gene model died. Comparing highest and lowest risk groups, the HR of lethal prostate cancer was 3.3 (95\% CI, 0.7-15.0). However, the model was also correlated with the clinical variables and after adjustment was less of a prognostic predictor (Table 2). The molecular signature was a poorer predictor of lethal prostate cancer (c-index 0.59) compared with clinical markers alone (c-index 0.71).

\section{Discussion}

In this cohort of men with initially untreated localized prostate cancer, we found the nine-gene model was not a useful discriminator of lethal versus indolent prostate cancer and did not add information to risk prediction. We tested the signature to predict prostate cancer death, which is the optimal outcome for validation of biomarkers of prostate cancer prognosis.

Table 2. Nine-gene model as a predictor of lethal prostate cancer, Örebro Watchful Waiting Cohort, 1977 to 2005

\begin{tabular}{|c|c|c|c|c|c|}
\hline & \multirow[t]{2}{*}{ Total $(n)$} & \multirow[t]{2}{*}{ Lethal* (\%) } & \multirow[t]{2}{*}{ Indolent $^{\dagger}(\%)$} & \multicolumn{2}{|c|}{ HR (95\% CI) } \\
\hline & & & & Age adjusted & Multivariable adjusted ${ }^{\ddagger}$ \\
\hline \multicolumn{6}{|l|}{ Molecular model only } \\
\hline Q1 (lowest risk) & 17 & 11.8 & 35.3 & Reference & Reference \\
\hline Q2 & 50 & 22.0 & 32.0 & $2.0(0.4-9.0)$ & $1.7(0.4-7.8)$ \\
\hline Q3 (intermediate risk) & 42 & 28.6 & 26.2 & $2.6(0.6-11.8)$ & $1.7(0.4-8.2)$ \\
\hline Q4 & 24 & 16.7 & 29.2 & $1.5(0.3-8.5)$ & $0.6(0.1-3.2)$ \\
\hline Q5 (highest risk) & 39 & 28.2 & 23.1 & $3.3(0.7-15.0)$ & $1.7(0.3-8.4)$ \\
\hline$P$ for trend & & & 0.17 & 0.78 & \\
\hline
\end{tabular}

*Lethal prostate cancer defined as men who developed distant metastases or died of cancer over follow-up.

tIndolent cancer based on long-term survival defined as 10 years or more without development of distant metastases or death from prostate cancer.

‡Hazard ratios and confidence intervals adjusted for age at diagnosis, Gleason score, nuclear grade, and tumor extent. 
Although biochemical failure is associated with an increased likelihood of cancer death, most men who experience a relapse would not die of their disease $(11,12)$.

Our cohort included prospective long-term and complete clinical follow-up, which is important because prostate cancer deaths can occur many years after diagnosis $(2,13)$. Our study population was derived from a well-defined catchment area, with similar clinical care for all patients, thus reducing potential selection biases. Although the Swedish Watchful Waiting Cohort was small, we had a relatively large number of events (40 lethals). Our study had $80 \%$ power to exclude for the nine-gene signature HR of 1.85 comparing extreme risk groups, a clinically meaningful risk estimate for biomarker studies. The tissue samples underwent standardized histopathologic review for Gleason grading to address potential grade migration over time (13). Although the Örebro cohort was assembled in the prePSA era, the cancers were incidentally detected and likely resemble PSA detected cases given the distribution of Gleason grade and stage. These TURP tended to be transitional zone as opposed to peripheral tumors, but there is little evidence to suggest meaningful differences in the biology of tumors in these zones. We had no baseline PSA levels, a clinical predictor of outcome (14-16). However, it is unlikely that such information would have altered our results.

Although we could not validate this nine-gene model, tumor biomarkers still hold promise to characterize a patient's prostate cancer prognosis to target appropriate therapy. Molecular tools can potentially distinguish men for whom aggressive treatment would be indicated and thereby reduce the number needed to treat to avoid one prostate cancer death. The challenge for the future is to use cohorts with appropriate clinical outcomes and follow-up for development and validation of molecular signatures.

\section{Acknowledgments}

We thank Kelly Lamb and Lela Schumacher for technical support critical to this study. The TMA arrays were constructed at the Dana-Farber/Harvard Cancer Center Tissue Microarray Core Facility.

\section{References}

1. Albertsen PC, Hanley JA, Fine J. 20-year outcomes following conservative management of clinically localized prostate cancer. JAMA 2005;293:2095-101.

2. Johansson JE, Andren O, Andersson SO, et al. Natural history of early, localized prostate cancer. JAMA 2004;291:2713-9.

3. Kattan MW, Eastham JA, Stapleton AM, Wheeler TM, Scardino PT. A preoperative nomogram for disease recurrence following radical prostatectomy for prostate cancer. J Natl Cancer Inst 1998;90:766-71.

4. Stephenson AJ, Scardino PT, Eastham JA, et al. Preoperative nomogram predicting the 10 -year probability of prostate cancer recurrence after radical prostatectomy. J Natl Cancer Inst 2006;98: 715-7.

5. Kattan MW, Shariat SF, Andrews B, et al. The addition of interleukin-6 soluble receptor and transforming growth factor $\beta 1$ improves a preoperative nomogram for predicting biochemical progression in patients with clinically localized prostate cancer. J Clin Oncol 2003; 21:3573-9.

6. Varambally S, Yu J, Laxman B, et al. Integrative genomic and proteomic analysis of prostate cancer reveals signatures of metastatic progression. Cancer Cell 2005;8:393-406.

7. Pound CR, Partin AW, Eisenberger MA, Chan DW, Pearson JD, Walsh PC. Natural history of progression after PSA elevation following radical prostatectomy. JAMA 1999;281:1591-7.

8. Andren O, Fall K, Franzen L, Andersson SO, Johansson JE, Rubin MA. How well does the Gleason score predict prostate cancer death? A 20-year followup of a population based cohort in Sweden. J Urol 2006;175:1337-40.

9. Rubin MA, Bismar TA, Andren O, et al. Decreased $\alpha$-methylacyl CoA racemase expression in localized prostate cancer is associated with an increased rate of biochemical recurrence and cancer-specific death. Cancer Epidemiol Biomarkers Prev 2005;14:1424-32.

10. Kim R, Demichelis F, Tang J, et al. Internet-based Profiler system as integrative framework to support translational research. BMC Bioinformatics 2005;6:304

11. D'Amico AV, Cote $K$, Loffredo $M$, Renshaw AA, Chen $\mathrm{MH}$. Pretreatment predictors of time to cancer specific death after prostate specific antigen failure. J Urol 2003;169:1320-4.

12. D'Amico AV, Cote $K$, Loffredo $M$, Renshaw AA, Schultz D. Determinants of prostate cancer specific survival following radiation therapy during the prostate specific antigen era. J Urol 2003; 170:S42-6; discussion S46-7.

13. Albertsen PC, Hanley JA, Barrows GH, et al. Prostate cancer and the Will Rogers phenomenon. J Natl Cancer Inst 2005;97:1248-53.

14. Cuzick J, Fisher G, Kattan M, et al. Long-term outcome among men with conservatively treated localized prostate cancer. Br J Cancer 2006; $95: 1186-94$.

15. D'Amico AV, Chen MH, Roehl KA, Catalona WJ. Preoperative PSA velocity and the risk of death from prostate cancer after radical prostatectomy. N Engl J Med 2004;351:125-35.

16. D'Amico AV, Renshaw AA, Sussman B, Chen MH. Pretreatment PSA velocity and risk of death from prostate cancer following external beam radiation therapy. JAMA 2005;294:440-7. 


\section{Cancer Epidemiology, \\ Biomarkers \& Prevention}

\section{Nine-Gene Molecular Signature Is Not Associated with Prostate Cancer Death in a Watchful Waiting Cohort}

Lorelei A. Mucci, Yudi Pawitan, Francesca Demichelis, et al.

Cancer Epidemiol Biomarkers Prev 2008;17:249-251.

Updated version Access the most recent version of this article at:

http://cebp.aacrjournals.org/content/17/1/249

Cited articles This article cites 16 articles, 2 of which you can access for free at:

http://cebp.aacrjournals.org/content/17/1/249.full\#ref-list-1

E-mail alerts Sign up to receive free email-alerts related to this article or journal.

Reprints and To order reprints of this article or to subscribe to the journal, contact the AACR Publications

Subscriptions Department at pubs@aacr.org.

Permissions To request permission to re-use all or part of this article, use this link http://cebp.aacrjournals.org/content/17/1/249.

Click on "Request Permissions" which will take you to the Copyright Clearance Center's (CCC)

Rightslink site. 